papers an introduction which, for originality, clarity, enjoyment, enthusiasm, and authority, could not be better. The editor of this volume, Dr. G. K. Batchelor, and its sponsors, the Ministry of Supply and Trinity College, Cambridge, are to be congratulated on their valuable enterprise. A. H. CotrrelL

\section{NUCLEAR PHYSICS AND ATOM BOMBS}

\section{Brighter Than a Thousand Suns}

The Moral and Political History of the Atomic Scientists. By Dr. Robert Jungk. Translated into English by James Cleugh. Pp. 350. (London: Victor Gollancz, Ltd., in association with Rupert Hart-Davis, Ltd., 1958.) 21s. net.

$\mathrm{D}$ R. ROBERT JUNGK attempts in this book to write "The Moral and Political History of the Atomic Scientists" or "the inside story behind the construction of the atomic and hydrogen bombs". The story is written largely around personalities, including Rutherford, Bohr, Heisenberg, Joliot-Curie, Kapitza, Fermi, Oppenheimer, Szilard and Teller. The author has obtained his knowledge at second hand by diligent inquiry from a galaxy of scientists whose help is acknowledged in the introduction.

The story opens with Rutherford's disintegration of nitrogen by $\alpha$-particles and rapidly switches to Göttingen to describe the life of the scientific notables of the day-Born, Frank, Klein, Heisenberg and Hilbert, with their numerous visitors, including Bohr, Blackett, Dirac, Oppenheimer and Pauli. It describes the dismissal of the seven Jewish professors from Göttingen, including Max Born and Courant, after Hitler's seizure of power, and follows this with a sympathetic account of Niels Bohr's Institute of Theoretical Physics in Copenhagen, referring to his "Castle of Carlsberg" and an amusing parody of Faust in which Bohr and Pauli were principal characters.

From here the story turns to Cambridge, where a highly inaccurate account of the Cavendish Labora. tory is given. The nuclear physicists, including Blackett, Oliphant, Feather and myself, are said to have worked as a kind of "subordinate section" directed by Kapitza. He refers also to Kapitza's "baby giants of high voltage". Nothing could be farther from the truth, for Kapitza took no part in experimental nuclear physics at this time. Kapitza's detention in the U.S.S.R. in 1934 is said to have had "a disruptive effect on the Cavendish as a whole" and "Rutherford's own mighty frame suddenly began to age". This again is more fiction than fact.

The narrative then moves to Rome and Fermi's work on the production of radioactivity by neutrons. The author discusses why fission was not discovered in these experiments, and suggests that physicists did not appreciate that neutrons might be able to penetrate the potential barrier of heavy elements. Since Fermi was producing radioactivity in many heavy elements this is nonsense. What the physicists and chemists failed for so long to realize was that processes other than the emission of protons, $x$-particles and electrons could take place. There is also an account of supposed friction between Madame Joliot and Madame Meitner resulting from the Solvay Conference of 1933. The discussions are reported verbatim in the Solvay Conference Papers and do not support this. These early chapters do not therefore provide high marks for the author's credibility or scientific knowledge.

After this the story goes on to the discovery of fission and thereafter to the war years and the 'uran. ium project' in Germany, which was directed entirely to producing a heavy water atomic pile and never to produce an atomic bomb. The narrator gives an account of discussions between Houtermans and Weizäcker in 1941, in which he states that the two agreed that the first and most important task of uranium policy must be to keep departments in the dark about the now imminent feasibility of manufacturing such bombs. The author's general thesis about the German atomic energy project is contrary to the conclusions of Goudsmit in "Alsos".

After this the story moves to the United States, to describe the origin of the atomic project in that country and the development of the Manhattan project, and then devotes two chapters to Oppenheimer's founding of Los Alamos and the development of the atomic bomb.

The author then gives an account of the discussions as to whether and how the atomic bomb should be used and describes the labours of the United States 'Interim Committee' which had to advise the President on this question. The Interim Committee had a scientific panel consisting of Oppenheimer, Fermi, A. H. Compton and E. O. Lawrence. These discussions have been described in much more detail and from first-hand knowledge in A. H. Compton's book "An Atomic Quest". Opinion on the scientific panel was divided as to whether and how the bomb should be used. There were similarly divided views among the staffs of the Chicago laboratories. However, the doubts of the scientists produced little effect, and Mr. Stimson, Secretary for War, has given his own account of the reasons, based on potential loss of American lives, which led him to advise that the bomb should be used. Dr. Jungk records General Grove's view that President Truman did "not so much say yes as not say no".

The story moves on to the years of McCarthyism in the United States and the investigation of Robert Oppenheimer. It retells the now familiar story of the debates as to whether the United States should develop the hydrogen bomb.

One chapter of the book is devoted to the Fuchs case. The author makes the remarkable and ridiculous suggestion that the Russians might have denounced Fuchs to the British Intelligence Service to upset Anglo-American relations.

The author concludes that these events have forced physicists to leave their 'ivory towers' and to be made aware of their responsibilities to the world.

The book as a whole is interesting, but it cannot be considered as an accurate historical account of these developments. JoHN COCKCROFT

\section{CO-OPERATIVE PHENOMENA}

\section{Changes of State}

A Mathematical-Physical Assessment. By H. N. V. Temperley. Pp. xi+324. (London: Cleaver-Hume Press, Ltd., 1956.) 50s. net.

7 THE term 'changes of state' would usually be taken to imply primarily the processes of fusion and evaporation for which, typically, the transition temperature is sharply defined. There are, however, many other changes of state which proceed more 